\title{
Medidas do ambiente acústico em creche de suínos
}

\author{
Késia O. da Silva ${ }^{1}$, Irenilza de A. Nääs², Yamilia B. Tolon², Leonardo S. L. Campos² \& Douglas D. Salgado²
}

\begin{abstract}
RESUMO
Atualmente, não apenas os elementos do ambiente térmico influenciam a produtividade dos suínos, mas, também, a interação com o ambiente aéreo gerado na instalação, junto com o nível de ruídos. Estudou-se, neste trabalho, o perfil do ambiente acústico dentro de um galpão de creche de suínos usando-se mapas de distribuição da média dos níveis de ruído, em função da temperatura e umidade relativa do ar. O ambiente construído foi dividido em células/quadrantes de $2 \mathrm{~m}^{2}$ e medidos, no centro geométrico no nível do leitão, o nível de ruído, a temperatura de bulbo seco e a umidade relativa do ar. Com os resultados mapeados, notou-se que o nível médio de ruído da creche foi de 12,49 dB mas não se encontraram correlações entre o ambiente térmico e o ambiente acústico. Os níveis de ruído obtidos estão abaixo dos valores preconizados internacionalmente para alojamento de suínos e dentro das normas nacionais vigentes para os trabalhadores da granja. Os resultados apontam que os leitões recém transferidos para a creche vocalizaram mais que aqueles que já estavam habituados ao ambiente $(10,98 \mathrm{~dB})$, resultando em nível médio de ruído superior $(12,58 \mathrm{~dB})$.
\end{abstract}

Palavras-chave: análise de ruídos, medida de bem-estar, comportamento

\section{Measurements of the acoustic environment in a pig nursery}

\begin{abstract}
Nowadays, it is known that not only thermodynamics elements influence swine productivity, but also the interaction with the aerial environment along with the noise level must be taken into account. This research studied the acoustic environment inside a pig nursery housing using average noise level distribution maps as a function of ambient temperature and relative humidity. The structural environment was divided in $2 \mathrm{~m}^{2}$ cells. Noise level, air dry bulb temperature and relative humidity were recorded at piglet height in the centre of each cell. The results were mapped and the resulting nursery noise level was found to be $12.49 \mathrm{~dB}$. However, a positive correlation between thermal environment and noise level was not found. From the results, it was possible to estimate the room noise level due to presence of piglets at around $12.49 \mathrm{~dB}$. The resulting noise level found was below the international limit for swine housing and in accordance to national standards for farm workers. The results indicate that the piglets that were recently transferred to that environment vocalized more than the ones already acquainted with the room $(10.98 \mathrm{~dB})$, presenting a higher level of noise (12.58 dB).
\end{abstract}

Key words: noise level analysis, welfare assessment, behavior

${ }^{1}$ ESALQ/USP. Av. Pádua Dias, 11, CP 9, CEP ...... Piracicaba, SP. Fone/fax: (19) 3429-4217. Ramal: 238. Email: kosilva@esalq.usp.br

2 FEAGRI/UNICAMP. CEP 13083-970, Campinas, SP. E-mail: irenilza@agr.unicamp.br; yamilia.tolon@agr.unicamp.br; douglas.salgado@agr.unicamp.br 


\section{INTRODUÇÃO}

A produção de suínos representa uma significativa parcela da economia nacional enquanto importantes transformações no mercado atingem a suinocultura brasileira e mundial nos últimos anos ressaltando-se, como uma das mais evidentes, a preocupação em se alcançar níveis desejáveis de bem-estar nos animais alojados e nos trabalhadores envolvidos com a atividade. Em condições tropicais o desconforto térmico é freqüente, constituindo-se ainda em um dos principais problemas da moderna suinocultura, sobretudo nas demandas para exportação, visto a urgente de medidas para redução de riscos na produção, tanto na saúde humana como animal, além de um dos pontos de que pouco se conhece, referente aos níveis de ruído nos ambientes criatórios de suínos, nas condições brasileiras.

Estudando as condições de alojamento em creche de suínos, Romanini \& Nääs (2003) verificaram a influência das condições ambientais nos níveis de ruído em dois diferentes sistemas de creche de suínos, medindo os níveis de ruídos gerados em salas de creche com gaiolas e em piso semi-ripado, no período de trabalho dos funcionários da granja (7:0017:00 h) e encontraram que o ruído emitido pelos animais foi relativo ao manejo de alimentação e ao desconforto térmico. De acordo com Gustafsson (1997), ruído acima de 100 dB(A) foi verificado na alimentação de suínos de forma manual.

Talling et al. (1996) estudaram as respostas fisiológicas dos suínos em situações induzidas de ruídos artificiais (intensidades e freqüências) e ruídos reais (transporte, granja e abatedouro) chegando à conclusão de que o som pode incentivar, nos suínos, a atitude de defesa por meio de mecanismos de vocalização (quando há perigo imediato ou alguma ameaça é identificada); entretanto, a manifestação desta resposta depende da característica dos estímulos sonoros e dos suínos se habituarem a esses ruídos. Em um trabalho subseqüente, estudando o ambiente acústico em alojamento, transporte abatedouro e pré-abate de suínos, Talling et al. (1998) encontraram que os sons aos quais os animais estavam expostos (níveis de pressão sonora variando de 76-96 dB, dependendo da etapa ou do evento específico a que os suínos estavam sendo submetidos) resultaram em vocalização que, por sua vez, pode estar relacionado ao medo do desconhecido.

Também Algers et al. (1978) informaram que suínos estão freqüentemente expostos ao som em valores maiores que $70 \mathrm{~dB}$ em abrigos artificiais. Embora Heffner \& Heffner (1990) não fizessem comparação direta entre humanos e a percepção dos suínos ao som, determinaram um limiar absoluto relacionado à curva de sensibilidade auditiva de suínos, a qual indica que esses animais têm alguma semelhança com a sensibilidade de freqüência para os humanos; entretanto, torna-se difícil uma comparação visto que os suínos não podem ouvir sons com movimentação controlada, enquanto os humanos, sim (Talling et al., 1996); entretanto, os resultados apresentados pelos autores sugerem que esses animais também podem mostrar diferentes níveis de aversão a diferentes tipos de sons, principalmente àqueles que indicam a presença de algo desconhecido ou de um predador.
Outra característica importante na avaliação do ruído ambiente ou da vocalização animal é o fato de que sua alteração ou medida pode representar uma ferramenta significante para se avaliar as condições de bem-estar animal. Estudos realizados por diferentes autores mostraram que os animais reagem a situações estressantes como, por exemplo, desmame, fome e dor, mostrando vocalizações de alta freqüência (Fraser, 1974; Marchant-Forde et al., 2003; Manteuffel et al., 2004); já Weary et al. (1999) e Manteuffel \& Schon (2002) defendem que a vocalização pode ser considerada uma medida de não conformidade com as condições de bem-estar dos suínos, o que foi corroborado por Marx et al. (2003), ao demonstrarem que leitões castrados sem anestesia emitem um ruído com freqüência e intensidade de pressão sonora distinta daqueles que são anestesiados, podendo identificar a intensidade da dor que sentem.

A vocalização é a geração ativa de sons com o uso de órgãos específicos que se constitui na expressão de determinado estado do animal que possa ocorrer espontaneamente ou ser o resultado de um evento externo. Técnicas modernas de análise de ruídos permitem a discriminação, análise e classificação de vocalização ou ruído específico sendo, portanto, um interessante indicativo das condições de bemestar de alojamento de um grupo ou de um indivíduo, em particular.

Apresenta-se, através deste trabalho, o estudo da estimativa de ruídos em um galpão de creche de suínos e de sua correlação com dados de temperatura e umidade relativa do ar.

\section{MATERIAL E MÉTODOS}

O experimento foi conduzido em uma granja comercial de produção de suínos (Granja Querência), localizada no município de Salto, SP, situado a $23^{\circ} 12^{\prime} 10^{\prime}$ " de latitude sul e a $47^{\circ} 17^{\prime} 35^{\prime \prime}$ de longitude oeste, com altitude média de $521 \mathrm{~m}$, no centro de uma região chamada Zona de Depressão Periférica do Estado de São Paulo, entre o Planalto Atlântico e a escarpa da Serra de Botucatu.

O galpão de alojamento de suínos na fase de creche, utilizado para o desenvolvimento do trabalho, se compunha de uma área de $700 \mathrm{~m}^{2}(50 \times 14 \mathrm{~m})$, com orientação leste-oeste, construído com paredes de alvenaria, pilares de concreto armado, pé-direito no beiral de $2,30 \mathrm{~m}$, telhado de telhas de fibrocimento com duas águas com lanternim (1,90 m de abertura horizontal) na inclinação de $12,8 \%$ e estrutura de tesoura de aço, com beiral de $0,85 \mathrm{~m}$.

Toda a instalação era contornada por um gramado e os suínos dispostos em grupos de 50 animais, dentro do galpão, em cujo interior havia uma divisória de alvenaria de ( $1 / 2$ tijolo) na altura de $1,0 \mathrm{~m}$, sendo cada lado com uma área de piso cimentado de 7,0 x 10,0 $\mathrm{m}^{2}$ e corredor de $1,0 \mathrm{~m}$ de largura no lado externo, para os serviços de rotina. Os fechamentos laterais eram de alvenaria ( $1 / 2$ tijolo) na altura de $1,0 \mathrm{~m}$, com cortina de ráfia, para controle ambiental; as baias continham um rebaixo de $0,50 \mathrm{~m}$ de largura por $0,10 \mathrm{~m}$ de profundidade junto à parede divisória, para escoamento da água dos bebedouros e descarga dos dejetos 
além de comedouro no piso, ao longo da parede divisória com o meio exterior. Na área central havia quatro comedouros de alvenaria com depósito de ração de $1,10 \mathrm{~m}$ de largura e 1,85 m de comprimento; a água era fornecida aos animais através de bebedouros tipo chupeta (oito em cada baia), além de haver um bebedouro tipo cocho, com água corrente, situado junto à parede divisória das baias.

A sala utilizada para o experimento se situava no centro da edificação e alojava 360 leitões (180 em cada baia), ou seja, um lote tinha 33 dias de idade e o outro 38 dias, que saiam da pré-creche com peso médio de 10,61 kg (33 dias de idade), perfazendo $0,39 \mathrm{~m}^{2}$ por animal no ambiente estudado.

O galpão foi dividido em células/quadrantes de $2 \times 2 \mathrm{~m}^{2}$ e as medidas de nível de ruído foram feitas no centro geométrico destes quadrantes a $1,5 \mathrm{~m}$ do piso e, nos casos limítrofes, a $1,5 \mathrm{~m}$ da parede. Os valores da temperatura e da umidade relativa do ar foram medidos no centro geométrico das células a 1,5 $\mathrm{m}$ do piso, fixando-se o eixo $\mathrm{X}$ e se variando o eixo Y. O tempo médio de medição gasto em cada quadrante foi de $2 \mathrm{~min}$.

$\mathrm{O}$ registro dos ruídos, da temperatura e umidade relativa ambientes em cada quadrante, foi aleatório e o experimento teve início no centro do primeiro quadrante sorteado. Para medida do nível médio de ruído $(\mathrm{dB})$ utilizou-se um decibelímetro da marca SL-130 (Sound Level Meter) de acordo com a norma NR-15 (Ministério do Trabalho e Emprego, 1978). Um termohigrógrafo digital da marca Termo-Meter foi usado para medir a temperatura $\left({ }^{\circ} \mathrm{C}\right)$ e a umidade relativa do ar $(\%)$.

Fez-se o estudo da distribuição média de nível de ruído nesta condição de alojamento em creche mediante a interpretação de mapas de superfície dos valores médios dos níveis de ruído $(\mathrm{dB})$, temperatura $\left({ }^{\circ} \mathrm{C}\right)$ e umidade relativa do ar (\%) simultaneamente em relação às situações do galpão na ausência e na presença de suínos (com diferentes idades, 33 e 38 dias) nos quadrantes, no horário das 14 às $17 \mathrm{~h}$, por se tratar do horário de maior vocalização. A escolha do horário se relaciona ao fato de que no horário da alimentação é maior nível o de ruído.

Com a coleta dos valores dos níveis de ruído, elaboramse gráficos de superfície para tornar possível a determinação de valores médios para cada situação específica e se analisaram duas situações: galpão de creche vazio (ausência de suínos) e com o galpão de creche cheio (presença de suínos). Os níveis de ruído relativos somente aos leitões, foram obtidos pela diferença entre os valores resultantes dos níveis de ruído obtidos pelo galpão de creche cheio, subtraídos daqueles provenientes do galpão de creche vazio (computam-se, assim, os ruídos de fundo, provenientes dos ruídos externos).

Com esses resultados procedeu-se à análise estatística, utilizando-se o programa computacional Minitab (2004) para o teste de mediana (Kruskal-Wallis) usado por Weary et al. (1999) e Marx et al. (2003) por se compor de dados não paramétricos; o teste de médias (t. Student) e a elaboração de gráficos boxplot, buscando-se relacionar a variação de ruído com a temperatura e umidade relativa do ambiente de alojamento, por intermédio de análise de regressão e da observação visual dos mapas de distribuição da média dos ruídos ambientais.

\section{RESULTADOS E DISCUSSÃO}

Obteve-se o resultado da distribuição média dos ruídos na creche por meio do mapa de superfície dos níveis de ruído ocorridos em cada célula/quadrante do galpão, em que as abscissas e ordenadas representam as distâncias (m) e o eixo $\mathrm{Z}$, o ruído $(\mathrm{dB})$, conforme mostrado na Figura 1A e $2 \mathrm{~B}$. Constatou-se, observando-se o mapa, que a maioria dos níveis de ruído ficou em torno de 72 a $76 \mathrm{~dB}$, ocorrendo um pico de $88 \mathrm{~dB}$ (ponto $\mathrm{A}$ ), devido ao grito de um indivíduo, no momento da medição.

Esses resultados estão em concordância com Talling et al. (1998) que encontraram, para um ambiente com ventilação natural, um nível de ruído médio de $63 \mathrm{~dB}$, considerado dentro da faixa admissível para o leitão. A própria atividade dos animais dentro do alojamento pode gerar interações sociais que, eventualmente, podem modificar o padrão usual dos níveis de ruído $(72-76 \mathrm{~dB})$, conforme observaram Talling et al. (1996).
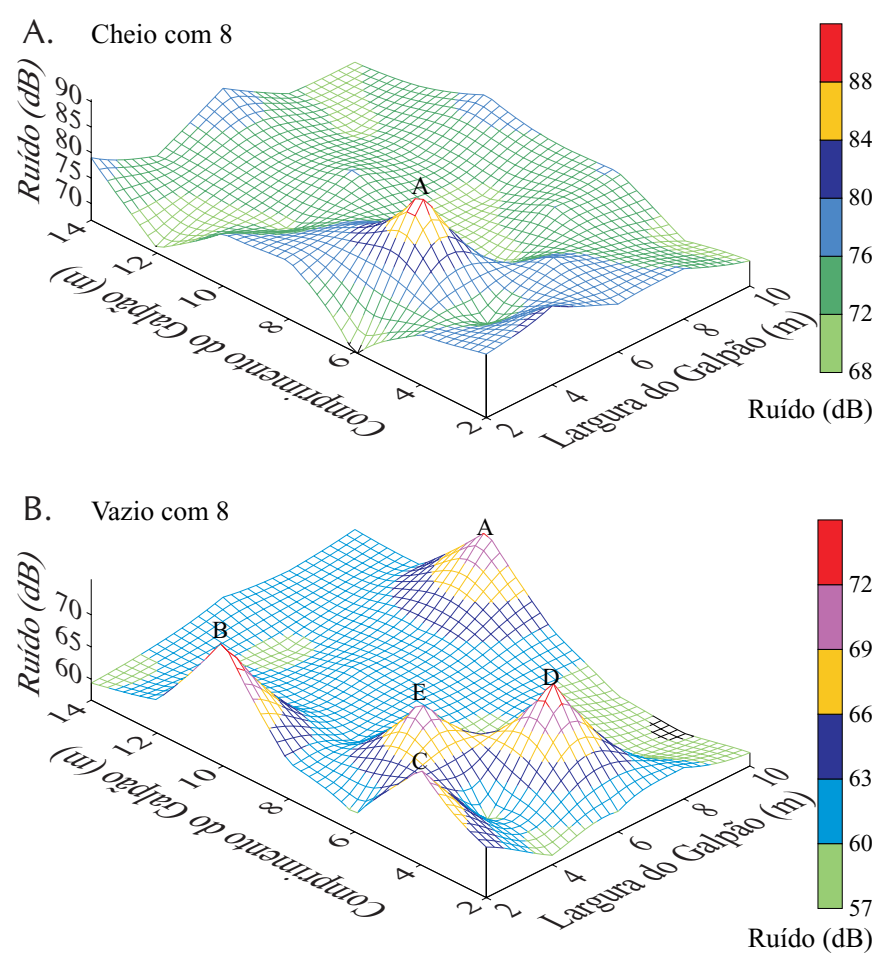

Figura 1. Mapa dos níveis de ruído no galpão de creche, ocupado com suínos (A) e mapa de níveis de ruídos de fundo no galpão de creche vazio (B)

Galpão de creche vazio: medida de nível de ruído de fundo

A Figura 1B mostra o mapa de níveis de ruído de fundo, resultante do galpão de creche vazio, ocorridos em cada célula/quadrante do galpão, onde as abscissas e ordenadas representam as distâncias $(\mathrm{m})$ e o eixo $\mathrm{Z}$, o ruído $(\mathrm{dB})$; constatou-se, também, que a maioria dos níveis de ruídos ficou em torno de 57 a $63 \mathrm{~dB}$. Os pontos A, B e C no gráfico onde ocorreram picos, estavam localizados na divisa de salas com outros suínos. Os pontos $\mathrm{D}$ e E, também indicam picos de níveis de ruído, devido a localização próxima às aberturas do galpão, ocorrendo a interferência de gritos de suínos de 
outros galpões, atividades de funcionários e uma torneira que apresentava vazamento. Algers et al. (1978) e Fraser (1974) enfatizaram a interferência de atividades externas e/ou interação dos tratadores como forma de alteração da vocalização dos animais, alojados ou não, sendo esta uma resposta natural ao desconhecido.

Nível de ruído do galpão de creche sem o ruído de fundo

O resultado dos valores de níveis de ruídos dos suínos alojados na creche obtidos pela diferença entre os ruídos do galpão cheio e o ruído de fundo (galpão vazio) pode ser observado na Figura 2. Os dados de ruído registrados foram representados por um gráfico de superfície, representando a distribuição média estimada de níveis de ruído na creche ocupada, sem o ruído de fundo, ocorrido em cada célula/ quadrante do galpão em que as abscissas e ordenadas indicam as distâncias $(m)$ e o eixo $Z$, o ruído $(d B)$. Observou-se, extraindo-se o ruído de fundo, que o nível de ruído do ambiente acústico da creche ficou em torno de $12,49 \mathrm{~dB}$ e que se pode observar alguns picos de ruídos, conforme representado pelo ponto $\mathrm{A}(22 \mathrm{~dB})$, devido à influência de ruído externo (vindo de gritos de um galpão de maternidade localizado ao lado). O ponto $\mathrm{B}(18 \mathrm{~dB})$ representa a divisória com outra sala de creche o que, de certa forma, influenciou na obtenção dos valores médios de nível de ruído. Esta variação não linear é prevista por Manteuffel et al. (2004), uma vez que a vocalização que gera ruído se deriva da interação entre os indivíduos do grupo de uma mesma região de alojamento, com grupos vizinhos.

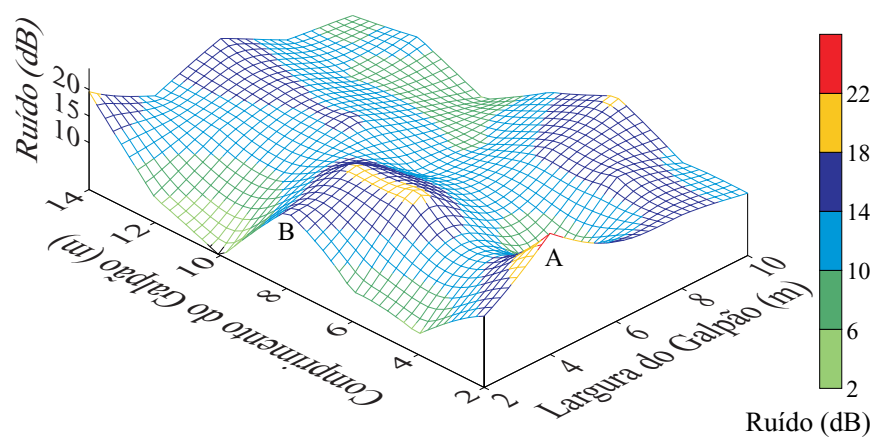

Figura 2. Mapa dos níveis de ruídos do galpão de creche, sem o ruído de fundo

\section{Comparação dos níveis de ruído para suínos de idade} diferente: sem o ruído de fundo

O mapa de níveis de ruído ocorrido em cada célula/quadrante do galpão com suínos de 33 dias e um outro para suínos com 38 dias, encontram-se nas Figuras 3A e 3B. Observou-se, pelos mapas de superfície, que a média dos níveis de ruído dos leitões mais novos foi em torno de $12,58 \mathrm{~dB}$, enquanto a média dos mais velhos ficou em torno de 10,98 dB. Em ambas as situações os níveis estão abaixo daqueles encontrados por Algers et al. (1978), que registraram níveis de ruído da ordem de $70 \mathrm{~dB}$ em criatórios de suínos.

Observou-se, também, maior variação nos níveis de ruído do galpão que alojava leitões mais novos, sendo que as extremidades apresentaram os valores mais altos; isto pode ter acontecido em virtude de interferência maior do ambiente externo do galpão.

Quanto aos resultados estatísticos, pode-se observar, pelo Boxplot mostrado na Figura 4, que não houve diferença nos níveis de ruído $(\mathrm{dB})$ para os suínos mais jovens, desconsiderando-se os pontos discrepantes (ruído de pico) nos mapas de representação esquemática; esta situação, por sua vez, pode ter ocorrido devido à fase de adaptação dos leitões recém-chegados do galpão de pré-creche, ao tentarem se familiarizar com o novo local, o que concorda com os resultados de Manteuffel et al. (2004). Como os suínos de 38 dias de idade já estavam no local há cinco dias, este período de familiarização pode ter contribuído para que, nesta condição, os níveis de ruído tenham sido mais baixos.
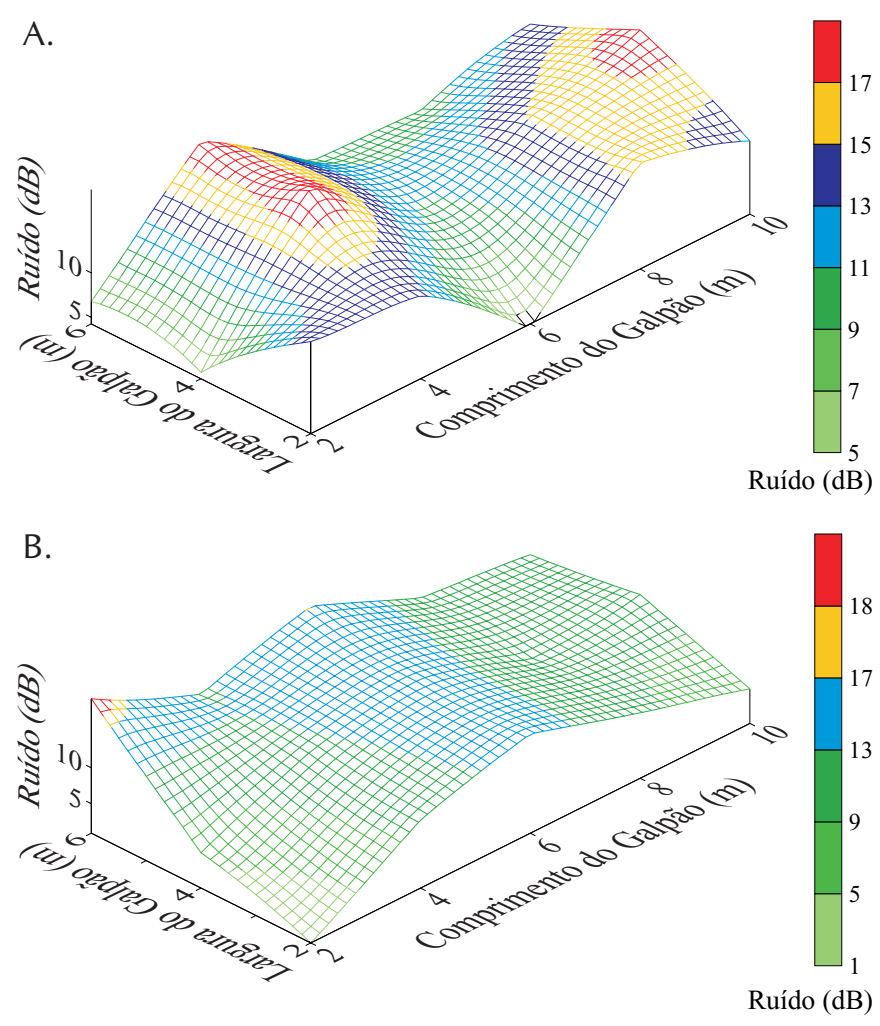

Figura 3. Representação esquemática dos valores dos níveis de ruído no galpão de creche, com suínos de 33 dias (A) e 38 dias (B)

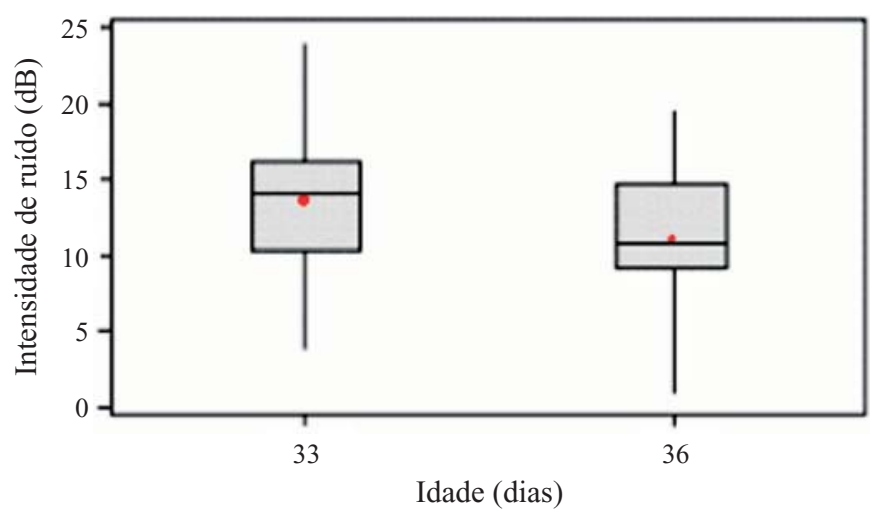

Figura 4. Gráfico representativo do perfil dos níveis de ruído com os leitões de idades diferentes (33 e 38 dias) 
De acordo com os testes Kruskal-Wallis (teste de mediana) e teste $\mathrm{t}$ Student (teste de médias), não houve evidências claras para que se rejeite a hipótese de que as intensidades de ruído entre as diferentes idades são iguais; entretanto, ocorreu maior diferença de variação dos níveis de ruído para os leitões mais jovens (33 dias) que para aqueles mais velhos (38 dias).

\section{Comparação das médias dos níveis de ruído dos suínos em relação às variáveis climáticas}

Para avaliar a relação existente entre a intensidade do nível de ruído ( $\mathrm{dB})$ e a temperatura de bulbo seco (TBS), utilizou-se a análise de regressão, podendo-se observar os resultados na Figura 5. Não se encontraram evidências $(\alpha=0,05)$ para se afirmar que existe associação entre a intensidade de ruído (dB) e TBS, com baixo coeficiente de determinação $\left(\mathrm{R}^{2}=0,015\right)$. Este resultado difere de Romanini \& Nääs (2003), que encontraram correlação entre o ambiente térmico dentro do alojamento e os níveis de ruído em creche, quando estudaram creches em gaiolas e em piso ripado, com concepção tipológica diferente do trabalho ora apresentado.

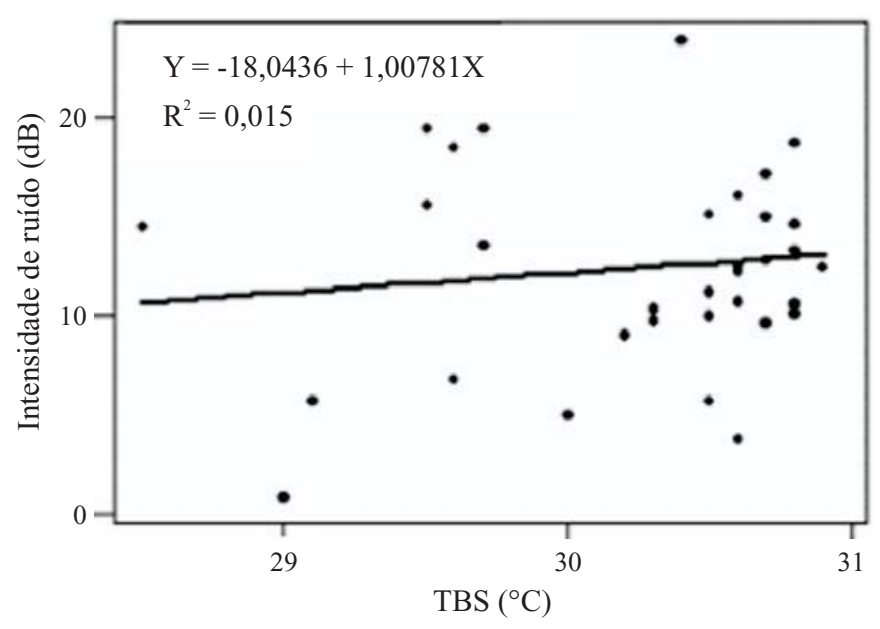

Figura 5. Intensidade de ruído em função da temperatura de bulbo (TBS)

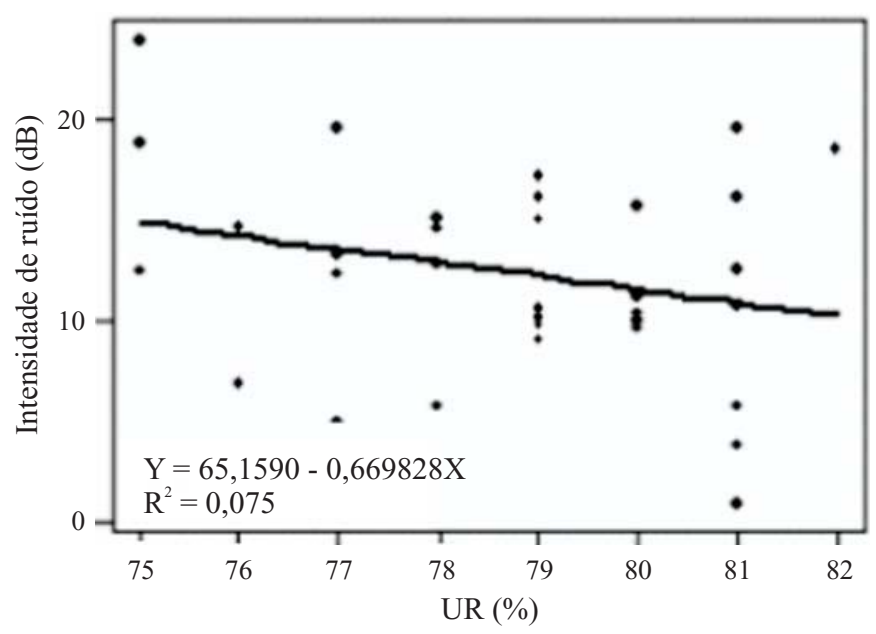

Figura 6. Intensidade de ruído em função da umidade relativa do ar (UR)
Também não se encontrou evidência $(\alpha=0,05)$ da influência da UR (\%) do ar na intensidade de ruído (dB), com valor baixo do coeficiente de determinação $\left(R^{2}=0,073\right)$, mostrado na Figura 6.

Este resultado leva à recomendação do alojamento coletivo em creche de suínos, uma vez que esta tipologia apresenta ambientes mais amplos e baixos níveis de ruído sendo, provavelmente, um tipo de alojamento que favorece o bem-estar animal.

\section{CONCLUSÕES}

1. De acordo com o cenário acústico encontrado, foi possível verificar que os valores médios de níveis de ruídos em dB no galpão de creche coletivo, com ventilação natural, estavam abaixo do preconizado na literatura mas dentro do permitido pela NR-15 para os trabalhadores da granja.

2. Então se encontrou um indicativo de que os leitões recém transferidos para a creche vocalizaram mais que aqueles que já estavam habituados ao ambiente $(10,98 \mathrm{~dB})$, resultando em nível médio de ruído superior (12,58 dB).

\section{AGRADECIMENTOS}

À Granja Querência, por permitir o desenvolvimento da pesquisa, ao Conselho Nacional de Desenvolvimento Científico e Tecnológico (CNPq) pela bolsa de pós-doutorado e ao Projeto PRODETAB/EMBRAPA, por financiar parte da pesquisa.

\section{LITERATURA CITADA}

Algers B.; Ekesbo I.; Stromberg S. The impact of continuous noise on animal health. Acta Veterinary Scandinavia, Uppsala, v.67, p.1-26, 1978. Supplement

Fraser, D. The vocalization and other behaviour of growing pigs in an "open field" test. Applied Animal Ethology, Frederiksbreg, v.1, n.1, p.13-16, 1974.

Gustafsson, B. The health and safety of workers in a confined animal system. Livestock Production Science, Amsterdan, v.49, p.191-202, 1997.

Heffner, R. S.; Heffner, H. E. Hearing in domestic pigs and goats. Hearing Research, Alberta, v.48, p.231-240, 1990.

Manteuffel, G.; Puppe, B.; Schön, P.C. Vocalization of farm animals as a measure of welfare. Applied Animal Behaviour Science, London, v.88, n.1-2, p.163-182, 2004.

Manteuffel, G.; Schon, P. C. Measuring pig welfare by automatic monitoring of stress calls. Bornimer: Agrartechnische Berichte Editor, 67p. 2002.

Marchant-Forde, J. N.; Bradshaw, H. R.; Marchant-Forde, M. R.; Broom, D. M. A note on the effect of gestation housing environment on approach test measures in gilts. Applied Animal Behaviour Science, London,v.80, n.4, p.28-296, 2003. 
Marx, G.; Horn, T.; Thielebein, J.; Knubel, B.; von Borell, E. Analysis of pain-related vocalization in young pigs. Journal of Sound and Vibration, Amsterdam, v.266, n.3, p.687-698, 2003. Ministério do Trabalho e Emprego. Portaria 3.214 de jul. 1978. Normas regulamentado-ras de segurança e saúde no trabalho (NR-15): Atividades e operações insalubres. Brasília, 1978. http://www.mte.gov.br/temas/segsau/legislacao/normas/nr 15 conteúdo. 14 Nov. 2001.

Minitab Statistical Software for Windows. Versão 12. 2004. http:/ /www.minitab.com/products/minitab/. 10 Fev. 2004.

Romanini, C. E. B.; Nääs, I. A. Determinação da influência do ambiente nos níveis de ruídos em dois tipos de creche de suínos
In: Congresso Interno de Iniciação Científica, 11, 2003, Campinas. Anais... Campinas: UNICAMP, Pró-Reitoria de Pesquisa, 2003, v.1, p.160-160.

Talling, J. C.; Lines, J. A.; Wathes, C. M.; Waran, N. K. The acoustic environment of the domestic pig. Journal of Agricultural Engineering Research, Silsoe, v.71, p.1-12. 1998.

Talling, J. C.; Waran, N. K.; Wathes, C. M.; Lines, J. A. Behavioural and physiological responses of pigs to sound. Applied Animal Behaviour Science, Londres, v.48, p.187-202, 1996.

Weary, D. M.; Appleby, M. C.; Fraser, D. Responses of piglets to early separation from the sow. Applied Animal Behaviour Science, Londres, v.63, n.4, p.289-300, 1999. 